\title{
A Microseismicity-Based Method of Rockburst Intensity Warning in Deep Tunnels in the Initial Period of Microseismic Monitoring
}

\author{
Guangliang Feng ${ }^{1,2}, * \mathbb{D}$, Manqing Lin ${ }^{3, *}$, Yang $\mathrm{Yu}^{4}$ and $\mathrm{Yu} \mathrm{Fu}^{4}$ \\ 1 State Key Laboratory of Geomechanics and Geotechnical Engineering, Institute of Rock and Soil Mechanics, \\ Chinese Academy of Sciences, Wuhan 430071, China \\ 2 Guangxi Key Laboratory of Disaster Prevention and Engineering Safety, Key Laboratory of Disaster \\ Prevention and Structural Safety of Ministry of Education, Guangxi University, Guangxi 530000, China \\ 3 School of Resources and Safety Engineering, Wuhan Institute of Technology, Wuhan 430071, China \\ 4 National Experimental Teaching Demonstration Center of Civil Engineering, East China Jiaotong University, \\ Nanchang 330013, China; lukeryuyang@163.com (Y.Y.); fuyuzfj@163.com (Y.F.) \\ * Correspondence: glfeng@whrsm.ac.cn (G.F.); manqing_lin@foxmail.com (M.L.)
}

Received: 21 April 2020; Accepted: 21 May 2020; Published: 27 May 2020

\begin{abstract}
Rockburst disasters in deep tunnels cause serious casualties and economic losses. It is a great challenge to make a warning for rockbursts in geotechnical engineering. In this work, a microseismicity-based rockburst intensity warning method is proposed that is suitable for use in deep tunnels in the initial period of microseismic (MS) monitoring. The method first involves collecting information on a sample of no more than five cases. Then, the event to be analyzed is combined with the sample events and subjected to cluster analysis. Finally, a rockburst intensity warning is generated according to the results of the cluster analysis or after a second cluster analysis. It is a comprehensive, multi-parameter rockburst intensity warning method that only needs a few rockburst cases for input which makes it suitable in the initial period of MS monitoring. The method also incorporates the novel idea of a second cluster analysis. An engineering application based on deep tunnels in the Jinping II hydropower station in Sichuan Province, China, shows that the rockburst intensity warning results based on the proposed method agree well with the actual situations in four tests carried out. The method will enrich the techniques used to warn of rockbursts based on microseismicity.
\end{abstract}

Keywords: rock mechanics; deep tunnel; microseismicity; rockburst intensity; warning; clustering analysis

\section{Introduction}

As society and the economy have developed, more and more tunneling projects are being undertaken. As the burial depths of such tunnels increase, rockbursts occur more frequently and more energetically. They not only cause mechanical damage and project delay, but also cause serious casualties and economic losses. A rockburst is defined as a sudden or violent collapse of an excavation and such events lead to seismic activity [1,2]. 'Rockburst damage' collectively refers to the direct damage caused to an underground cavern by a rockburst and also the indirect damage to the engineering area, support system, and ground buildings caused by the rockburst. They caused a great deal of damage to the deep tunnel construction in the project of Jinping II hydropower station in China, especially the extremely intense one that occurred in the drainage tunnel on 28 November, 2009. Seven deaths, one injury and destruction of the tunnel boring machine were brought by this event [3]. During the deep tunnel construction of the Neelum-Jhelum hydropower project in Pakistan, an extremely intense rockburst occurred on 31 May, 2015 [4,5]. It caused the tunnel's shape to change, broke the support 
measures put in place, and led to a serious delay in the project (roughly seven months were wasted cleaning away the resulting debris and reinforcing the support measures). Therefore, the ability to effectively warn the impending occurrence of rockbursts has become a major issue that urgently needs to be solved, especially in tunnels that are deep and pass through hard rock. This problem is thus pivotal to construction in many fields, e.g., the engineering of hydraulic and hydropower stations, traffic tunnels, national defense, and mining [1-16].

Microseismic (MS) monitoring technology is a three-dimensional, real-time monitoring technique that can be used to assess rockmass stability. As such, it has become a basic tool for investigating and managing rockbursts in deep mines and tunnels [5-12,16-36]. Scholars have also, to some degree, successfully used MS monitoring information to warn of rockburst occurrence. For example, Mendecki [6] systematically described a quantitative MS monitoring method and outlined its application in mines. The suggested method uses energy index, accumulative apparent volume, Schmidt number, and the values of $a$ and $b$ in the Gutenberg-Richter relationship to monitor and warn of rockburst risk. Tang [8] proposed an early-warning model for the nucleation of rockbursts based on MS monitoring which was put into practice in the Dongguanshan copper mine in China. Liu et al. [22] proposed a method for large-scale cracking and rockburst disasters warning based on multiple seismic parameters which was successfully used in the Hongtoushan copper mine. Ma et al. [36] studied some characteristics microseismicity of rockburst and fall of ground and used the MS source parameters of seismic energy, seismic moment, and apparent stress together to make a rockburst warning. The above MS methods for rockburst warning focus on the rockburst risk but not on the intensity of the rockburst. Rockburst intensity can be used to distinguish the severity of the rockburst failure. Accordingly, rockbursts can usually be divided into four intensity categories: extremely intense, intense, moderate, and slight [29]. The rockburst intensity can be used as the basis and premise for selecting reasonable rockburst mitigation methods, formulating correct rockburst mitigation strategies, and designing suitable support measures. A reasonable mitigation strategy and support design should meet certain objective requirements to ensure construction can be carried out safely, rapidly, and efficiently depending on the ascertained rockburst intensity risk. Rockburst intensity warning is one of the basic tasks of disaster prevention and reduction in underground engineering. In 2015, Feng et al. [11] proposed a quantitative, microseismicity-based warning method for rockburst intensity. The warning method was based on the long-term MS monitoring conducted in the deep tunnels of the Jinping II hydropower station. It involved a large number of rockburst cases and associated MS monitoring data. The method is able to provide a real-time warning of the possibility of rockbursts of different intensities occurring and can produce remarkable results when there are many rockburst cases that can be studied beforehand-the successful application of the method illustrates its applicability. In 2019, a method for predicting rockbursts in the deep tunnels based on MS monitoring and an optimized probabilistic neural network model was proposed [16]. This method also requires the use of a large number of rockburst cases and their associated MS monitoring data. In the initial stages of any MS monitoring program, however, there will only be a small number of rockburst cases available for study. Therefore, as there is only a small dataset of rockburst cases, any of the existing MS warning methods aimed at rockburst intensity will be ineffective in deep tunnels.

In this paper, a MS rockburst intensity warning method is proposed for use in deep tunnels that only requires a small dataset of rockburst cases and is therefore applicable during the initial period of MS monitoring. Cluster analysis (which is based on the idea that "birds of a feather, flock together") is used to classify the MS monitoring data and the results used to formulate a rockburst intensity warning. Some rockbursts with different intensities occurred in the deep tunnels of the Jinping II hydropower station in Sichuan Province, China, were used to test the proposed warning method. The maximum depth of the tunnels is $2525 \mathrm{~m}$. The methodology will enrich the current list of available techniques for rockburst warning in deep tunnel, infrastructure components (i.e., bridges-retaining walls) stability analysis, etc., based on microseismicity. The warning and analysis results can be 
used to guide the excavation process to mitigate the rockburst risk in deep tunnels, maintaining of infrastructure components, etc., in the initial period of MS monitoring.

\section{The Novel MS Rockburst Intensity Warning Method}

\subsection{General Outline of the Method}

The novel warning method that is suitable for use in the initial MS monitoring period requires only a small sample of rockburst cases and is established using the idea of clustering. The processes involved in the rockburst intensity warning method are illustrated in Figure 1.

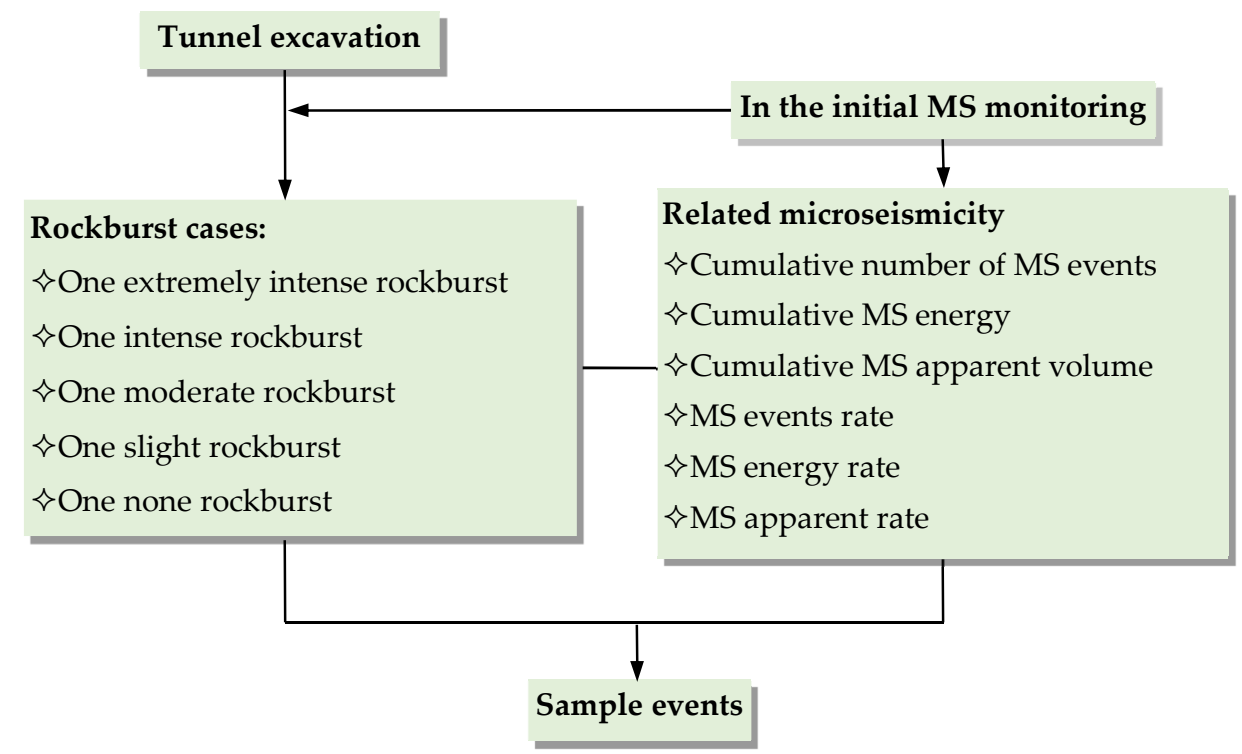

(a)

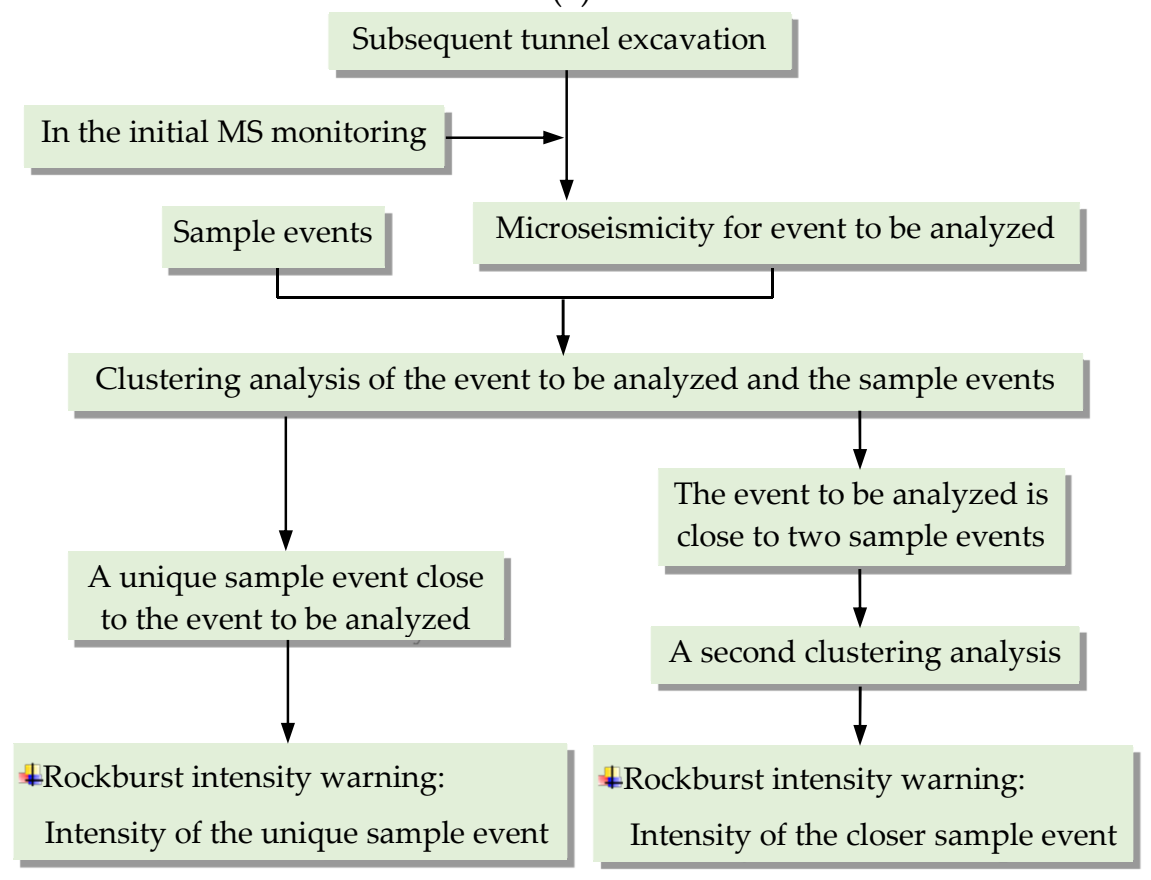

(b)

Figure 1. Flowcharts illustrating the processes involved in the MS rockburst intensity warning method in deep tunnels: (a) establishment of the set of sample events, and (b) generating rockburst intensity warnings during the subsequent tunnel excavation (in the initial MS monitoring period). 
The procedures involved are split into four steps, as follows:

Step I: In the initial MS monitoring period, data are collected on a small number of rockbursts as the tunnel is excavated together with the associated MS information occurring just before the rockbursts happened. The data collected should relate to rockbursts whose intensities can be classified as 'extremely intense', 'intense', 'moderate', 'slight', and 'none' (the 'none' category means that no rockburst occurred). One typical rockburst case from each intensity category is selected but it does not matter if no rockbursts occurred in a particular category.

In order to avoid the limitations and bias involved in basing rockburst warnings on a single MS parameter, multiple MS parameters are adopted [6,11,22-24]. The MS parameters selected should relate closely to the microfracturing occurring in the development process of rockburst and be capable of reflecting the evolution of the rockbursts. In this work, six common MS parameters are chosen to generate the rockburst intensity warning: cumulative number of MS events, cumulative MS energy, cumulative MS apparent volume, MS event rate, MS energy rate, and MS apparent rate (as shown in Figure 1). These are some of the most basic parameters employed in such studies. They have also been widely used for rockburst analysis, prediction, and warning in a large body of research [5-9,11,12,16-32]. The cumulative number of MS events describes the degree of the fractures in a certain part of the rockmass. The cumulative MS energy and cumulative MS apparent volume are a measure of the intensity and size of the fractures, respectively. The fracture property in rockmass can be expressed by combining these parameters with appropriate time factors [5]. The six intensity-related MS parameters determined for the selected rockburst cases are used to form the 'sample events'.

Step II: The microseismicity occurring in a particular area of study is monitored in real-time during tunnel excavation. The real-time MS data are used to extract the abovementioned six MS parameters for events that need to be analyzed.

Step III: The data on an event to be analyzed are combined with the sample events and subjected to cluster analysis. Specific details of the clustering analysis process are presented in Section 2.2.

Step IV: The cluster analysis allows the sample event (or events) that are closest to the event to be analyzed to be determined. When there is a unique sample event close to the event to be analyzed, the rockburst intensity of the former is taken to be a good measure of that of the event to be analyzed and used to generate a rockburst intensity warning. When the event to be analyzed is close to two sample events, the event to be analyzed is combined with the two sample events and subjected to a second cluster analysis. The rockburst intensity of the sample event which then turns out to be closer to the event to be analyzed is taken to be the rockburst intensity warning result for the event to be analyzed.

\subsection{Clustering Analysis}

Clustering analysis [37] is an analysis method based on the characteristics of the research objects. It classifies a group of samples or variables by their degree of affinity which can be described by computing a 'distance'. There are many metrics that can be used to compute this distance, the most commonly used ones being Euclidean distance, absolute distance, and Chebyshev distance. For example, distance can be calculated using the following expression:

$$
d_{r s}(m)=\left(\sum_{u=1}^{n}\left|x_{r u}-x_{s u}\right|^{m}\right)^{1 / m}
$$

where $d_{r s}$ is the distance between samples $r$ and $s, x_{r u}$ and $x_{s u}$ are the values of the $u$-th parameter in samples $r$ and $s$, respectively, $m$ is a constant and $n$ is the number of evaluation indices. When $m=1$, the absolute distance is computed and $m=2$ corresponds to the Euclidean distance. In this paper, the clustering analysis process is implemented using the following steps:

(1) The MS data are first normalized for each of the six parameters (i.e., that for the event to be analyzed and the sample events). This makes the information on the MS parameters more 
uniform and ensures that the transformed values lie in the range $0-1$. Transformation is carried out using the following formula:

$$
x_{i j}^{*}=\left(x_{i j}-x_{j}^{\min }\right) /\left(x_{j}^{\max }-x_{j}^{\min }\right)
$$

where $x_{i j}$ is the value of MS parameter $j$ in the $i$-th case, $x_{j}^{\min }$ and $x_{j}^{\max }$ are the minimum and maximum values of MS parameter $j$ amongst all cases, respectively, and an asterisk is used to denote the transformed value of $x_{i j}$.

(2) The event to be analyzed and the sample events are regarded as independent classes. We calculate the distance between these various classes and merge the nearest two classes into one class. Equation (1) with $m=2$ is used to get the distance in this paper.

(3) We calculate the distances between the classes that are left and merge the nearest two classes into one class. If the number of remaining classes is greater than 1 , then we continue the calculating and merging processes until all the samples belong to one class.

(4) After the completion of the clustering process, we draw a cluster graph and output the clustering results.

\section{Application Example}

\subsection{Project Overview}

The proposed method was applied to the deep tunnels of the Jinping II hydropower project which is located on the Yalong River, Sichuan Province, in southwestern China (Figure 2). The project has four headrace tunnels, each with an average length of about $16.7 \mathrm{~km}$. In addition, there are one drainage tunnel and two auxiliary tunnels.

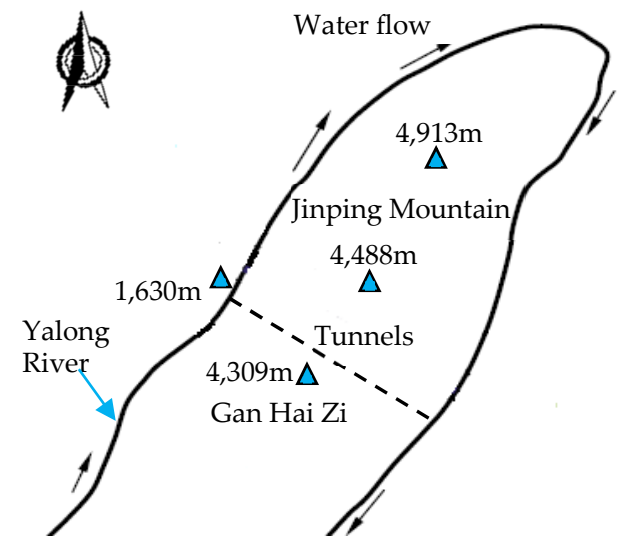

(a)

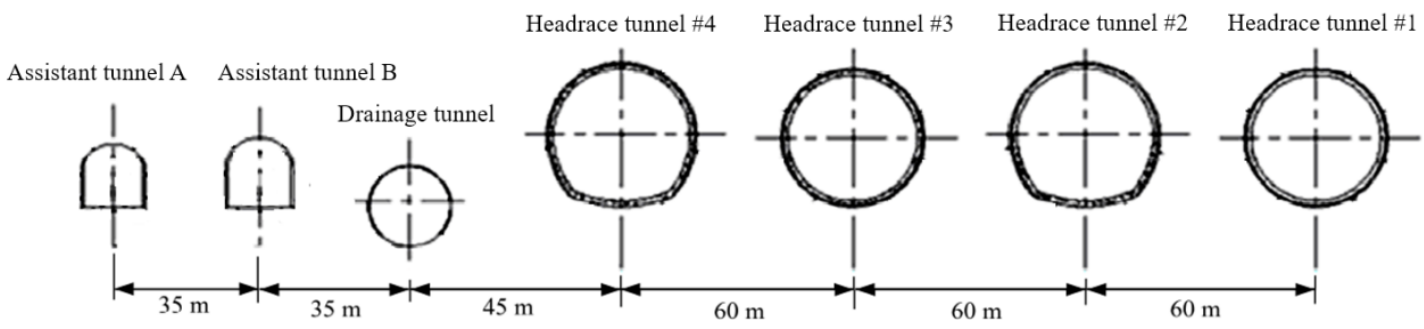

(b)

Figure 2. Details of the Jinping II hydropower station, showing: (a) the general layout of the power station with respect to the mountains and Yalong River; (b) the arrangement and cross-section of the deep tunnels therein [16]. 
The tunnels mainly pass through Triassic $(\mathrm{T})$ carbonate and some sand/slate strata along with chlorite/schist strata in local areas. Chlorite schist of the lower series (T1) and marble of the Yantang (T2y), Baishan (T2b), Zagunao (T2z) formation of the Triassic system. Type II and type III are the main components of rockmass, that is, the intact and brittle surrounding rocks which are characterized by stable lithological interfaces, dense structures, and pure components. The uniaxial compressive strengths, elastic moduli, and deformation moduli of the rocks lie in the ranges 55-114 MPa, 25-40 GPa, and 8-16 GPa, respectively. Consistent with the regional tectonic stress field, with the increasing of overburden, the principal geostress field changes from NE-SW to NWW-SEE. The maximum principal stress is $\sim 70 \mathrm{MPa}$, and the overburden of headrace tunnel and drainage tunnels is between $1900-2525 \mathrm{~m}$. The above detail of the information is described by Feng [5]. More detailed information on the project can be found in other related literatures $[3,10,28,38]$.

Rockbursts occurred frequently during the deep tunnel construction in the project. One typical rockburst destructive geomechanical phenomena that took place under the conditions of the project is given as follows. A very serious rockburst occurred in the SK9 + 283-Sk9 +313 drainage tunnel on 28 November, 2009. As shown in Figure 3, the rockburst resulted in the destruction of all support systems, with a total collapse of more than $400 \mathrm{~m}^{3}$. The main beam of the TBM equipment was broken and about 30 meters behind the cutter head was buried. Moreover, the shock wave of the rockburst caused the door of duty room on the second floor of standby system to be broken. Most of the rockmasses in the rockburst area are thick, gray and off-white, medium-fine-grained crystalline massive marbles which contain fresh hard calcite, pinstriped biotite and other minerals. Some flat rigid structural surfaces with scratches were presented in the rockburst area. When the rockburst occurred, a rigid fault with NWW direction, which was nearly parallel to the tunnel axis, was exposed. It was straight and smooth, has no filling, and its dip angle was approximately $50^{\circ}$. In addition, the rockmass under the fault collapsed and it formed a "V"-shaped failure zone with a depth of seven meters. The series of rockbursts in this tunnel may be influenced by the sudden slip of the fault caused by excavation. One of the important external factors that affects the occurrence of rockburst was that the tunnel section was located in the core of the fold syncline, and the structure was more intense tectonics than other tunnel sections, resulting in local stress concentration. The details of the rockburst are described by Zhang et al. [39]. In addition, there were over 270 rockbursts that occurred in the two auxiliary tunnels.

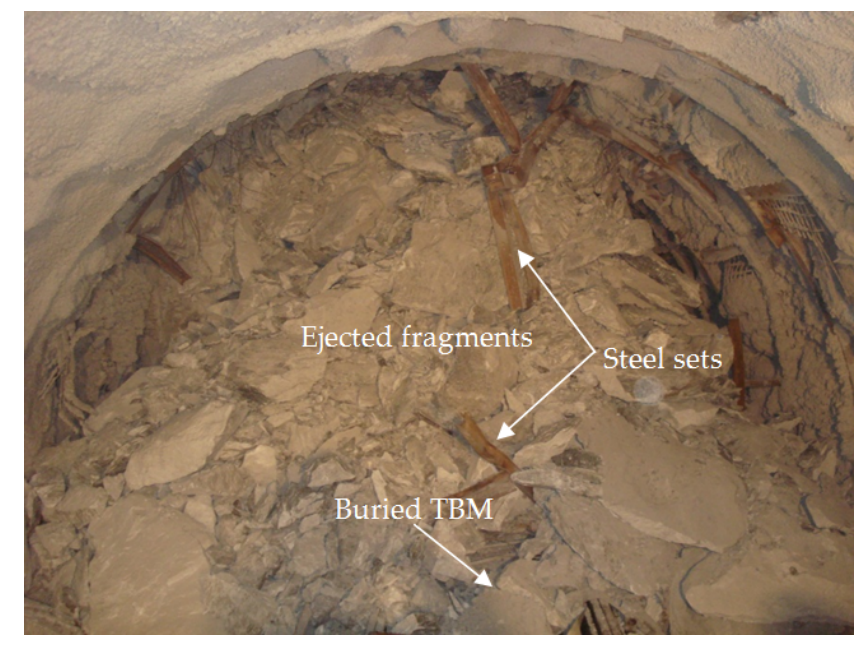

Figure 3. The extremely intense rockburst occurred on 28 November, 2009, in the drainage tunnel of the Jinping II hydropower station, China [16].

MS monitoring was conducted in several parts of the headrace tunnels \# $1-4$ and drainage tunnel of the project to alert workers to the impending occurrence of rockbursts and reduce the risk of losses being incurred due to them (Figure 4). Further details of the MS monitoring employed were described in other related literatures $[5,38]$. 


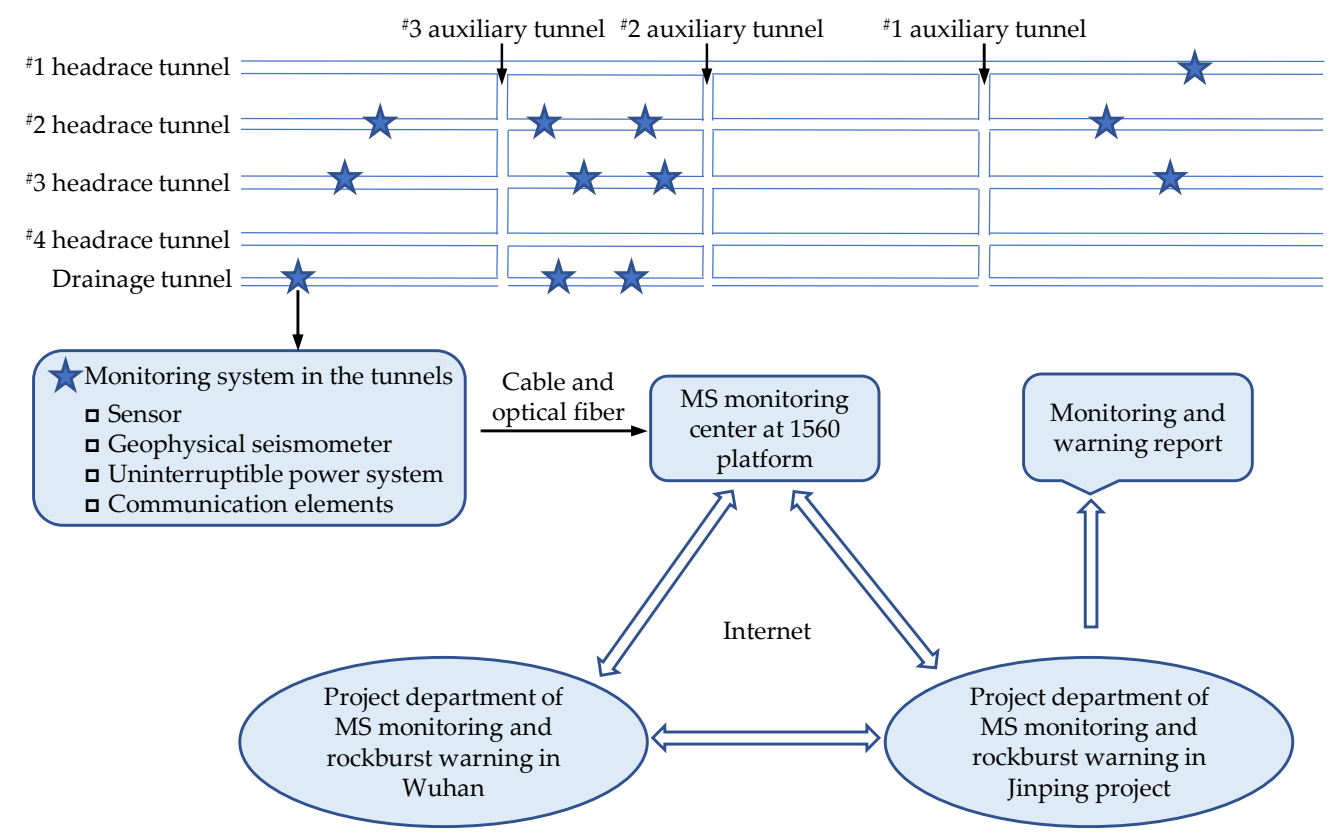

Figure 4. Communication network created to monitor rockbursts occurring in the tunnels of the Jinping II hydropower station in China.

\subsection{Rockburst Intensity Warning Process}

\subsubsection{Step I: Sample Events}

During the deep tunnel construction, a small sample of events consisting of four cases was formed during the initial MS monitoring period. Details of these four cases (rockburst intensities and related MS parameters) are shown in Table 1. The sample consists of one rockburst in each of the four categories: intense, moderate, slight, and none. No extremely intense rockburst occurred during the initial MS monitoring period. The microseismicity parameters in Table 1 are derived from the information recorded by the MS monitoring system in the corresponding rockburst development processes. They consist of six measures of MS activity (cumulative number of MS events, cumulative MS energy, cumulative MS apparent volume, MS event rate, MS energy rate, and MS apparent volume rate).

Table 1. Details of the sample events.

\begin{tabular}{|c|c|c|c|c|c|c|c|}
\hline \multirow[b]{2}{*}{$\begin{array}{c}\text { Sample } \\
\text { No. }\end{array}$} & \multirow[b]{2}{*}{$\begin{array}{l}\text { Rockburst } \\
\text { Intensity }\end{array}$} & \multicolumn{6}{|c|}{ Microseismicity } \\
\hline & & $\begin{array}{l}\text { Cumulative } \\
\text { Number of } \\
\text { MS Events }\end{array}$ & $\begin{array}{l}\text { Cumulative } \\
\text { Energy, } \\
\log (E / J)\end{array}$ & $\begin{array}{c}\text { Cumulative } \\
\text { Apparent } \\
\text { Volume, } \\
\log \left(V / \mathrm{m}^{3}\right)\end{array}$ & $\begin{array}{c}\text { Event } \\
\text { Rate (/d) }\end{array}$ & $\begin{array}{c}\text { Energy } \\
\text { Rate, } \\
\log \left(E_{r} /(\mathrm{J} / \mathrm{d})\right)\end{array}$ & $\begin{array}{c}\text { Apparent } \\
\text { Volume Rate, } \\
\log \left(V_{r} /\left(\mathrm{m}^{3} / \mathrm{d}\right)\right)\end{array}$ \\
\hline 1 & Intense & 22 & 5.859 & 4.895 & 2.2 & 4.859 & 3.895 \\
\hline 2 & Moderate & 19 & 3.680 & 4.832 & 1.9 & 2.680 & 3.832 \\
\hline 3 & Slight & 29 & 3.882 & 4.156 & 2.9 & 2.882 & 3.156 \\
\hline 4 & None & 6 & 5.300 & 2.735 & 1.5 & 4.698 & 2.133 \\
\hline
\end{tabular}

\subsubsection{Step II: The Events to Be Analyzed}

In the subsequent period of MS monitoring, four test cases (labeled Test 1-4) were selected to use as examples to probe the performance of the proposed rockburst intensity warning method. The warning results obtained were then compared with the actual behavior encountered to judge the adaptability and correctness of the proposed method. The MS activity monitored in real-time for each of the four cases was used to generate sets of MS parameters as before (Table 2). Test cases 1-4 correspond to the 
events to be analyzed using our proposed method. The cases are illustrated in more detail in Figure 5 to highlight the spatial distributions and energies of the MS events occurring.

Table 2. Rockburst cases used for testing.

\begin{tabular}{|c|c|c|c|c|c|c|c|}
\hline \multirow[b]{2}{*}{ Test No. } & \multirow[b]{2}{*}{$\begin{array}{l}\text { Rockburst } \\
\text { Intensity }\end{array}$} & \multicolumn{6}{|c|}{ Microseismicity } \\
\hline & & $\begin{array}{l}\text { Cumulative } \\
\text { Number of } \\
\text { MS Events }\end{array}$ & $\begin{array}{c}\text { Cumulative } \\
\text { Energy, } \\
\log (E / \mathrm{J})\end{array}$ & $\begin{array}{c}\text { Cumulative } \\
\text { Apparent } \\
\text { Volume, } \\
\log \left(V / \mathrm{m}^{3}\right)\end{array}$ & $\begin{array}{c}\text { Event } \\
\text { Rate (/d) }\end{array}$ & $\begin{array}{c}\text { Energy } \\
\text { Rate, } \\
\log \left(E_{r} /(\mathrm{J} / \mathrm{d})\right)\end{array}$ & $\begin{array}{c}\text { Apparent } \\
\text { Volume Rate, } \\
\log \left(V_{r} /\left(\mathrm{m}^{3} / \mathrm{d}\right)\right)\end{array}$ \\
\hline 1 & Intense & 15 & 6.587 & 5.152 & 1.7 & 5.633 & 4.198 \\
\hline 2 & Moderate & 24 & 4.748 & 4.660 & 4.0 & 3.970 & 3.882 \\
\hline 3 & Slight & 22 & 4.736 & 4.133 & 1.0 & 3.374 & 2.771 \\
\hline 4 & None & 7 & 4.300 & 3.018 & 0.8 & 3.345 & 2.064 \\
\hline
\end{tabular}

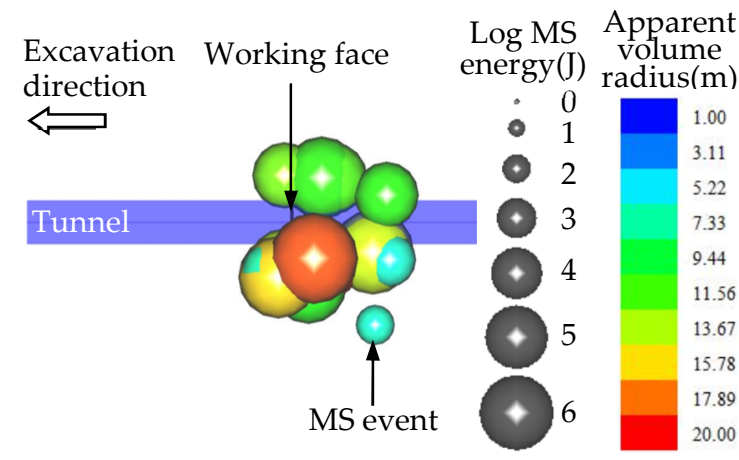

(a)

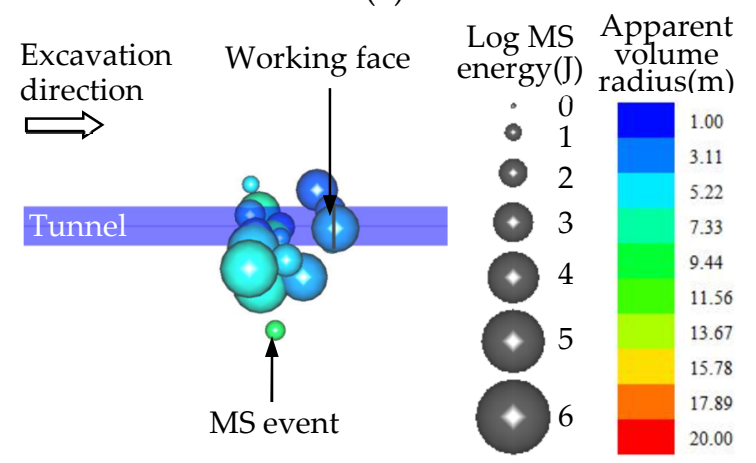

(c)

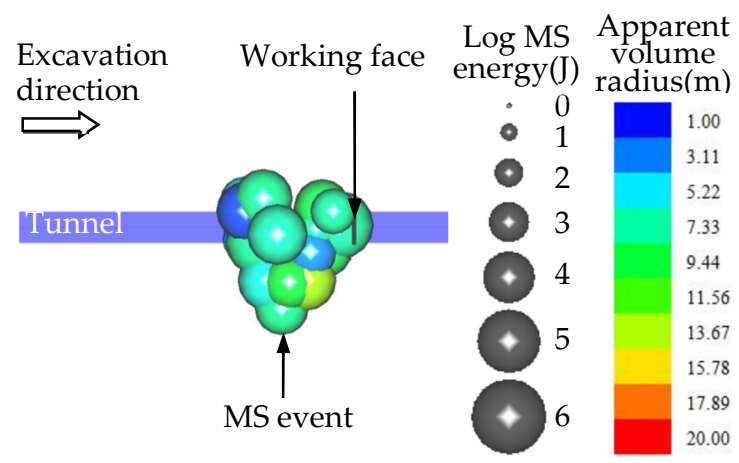

(b)

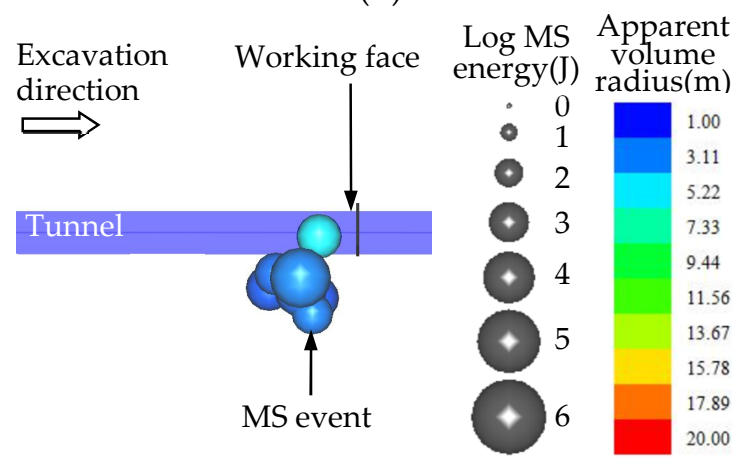

(d)

Figure 5. Spatial distributions and energies of the MS events associated with the test cases: (a) Test 1; (b) Test 2; (c) Test 3; (d) Test 4.

\subsubsection{Step III: Cluster Analysis}

The events to be analyzed were put together with the sample events for cluster analysis. The cluster analysis was carried out according to the process detailed in Section 2.2 and a further illustration of the pseudocode employed is presented in the Appendix A.

\subsubsection{Step IV: Rockburst Intensity Warning}

According to the results of the cluster analyses, the sample event closest to the event to be analyzed can be determined. Rockburst intensity warnings for the four rockburst cases used for testing were then given based on the sample event closest to the event to be analyzed. 


\subsection{Results}

The results of the cluster analyses carried out for the four cases to be analyzed are shown in Figure 6. We discuss each case in turn as follows.

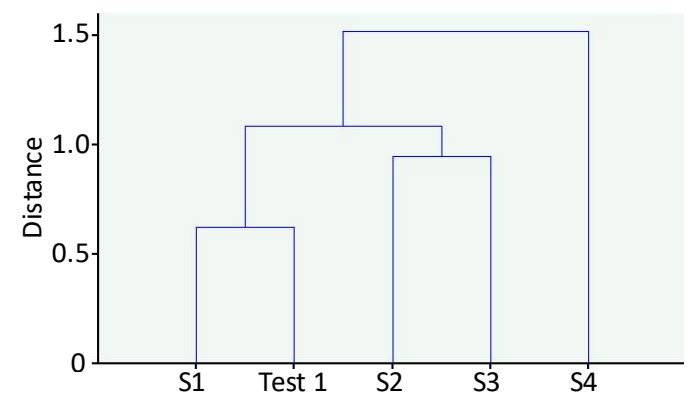

(a)

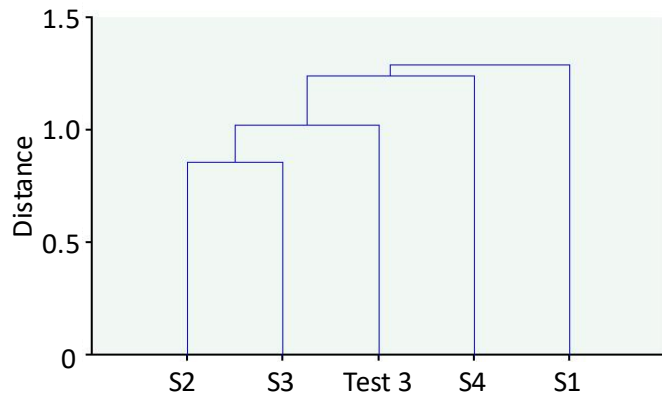

(c)

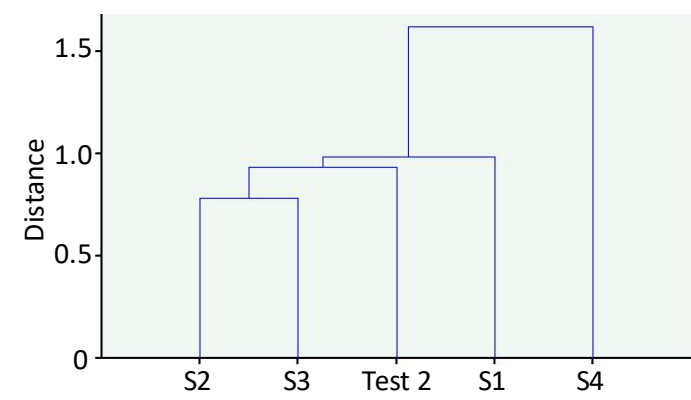

(b)

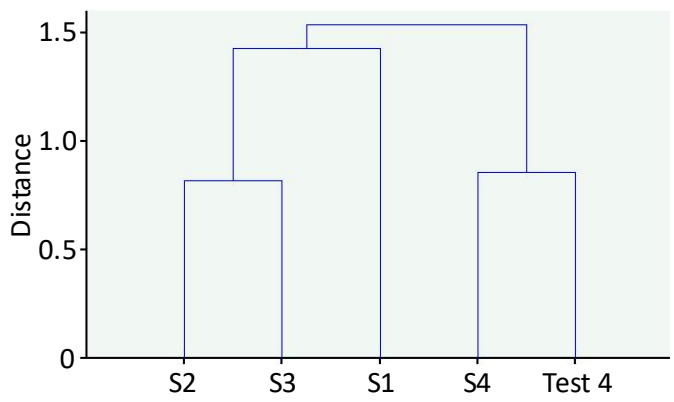

(d)

Figure 6. Results of the clustering analyses performed for cases: (a) Test 1; (b) Test 2; (c) Test 3; (d) Test 4. S1, S2, S3, and S4 denote the Sample 1, Sample 2, Sample 3, and Sample 4, respectively.

In the case of Test 1 , the event to be analyzed is classified into a group with Sample 1 that is far away from the other three sample cases, as shown in Figure 6a. Sample 1 corresponds to the occurrence of an intense rockburst which means that Test 1 exhibits microseismicity that is similar to that encountered during the development of an intense rockburst (Sample 1). This indicates that there is a potential risk of an intense rockburst forming and so the rockburst intensity warning result for Test 1 is 'intense rockburst'. The actual rockburst intensity found in Test 1 is shown in Table 2 and is in good agreement with the predicted behavior. The actual rockburst that occurred is further illustrated in Figure 7. It is an intense rockburst at the sidewall of the tunnel, with the depth of failure exceeding $1 \mathrm{~m}$.

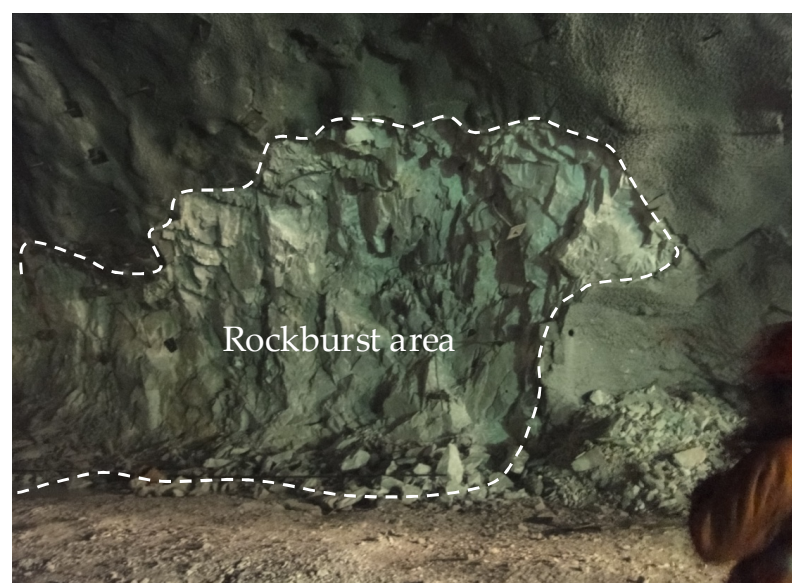

Figure 7. Photograph of the rockburst that occurred following the MS events recorded and analyzed in Test 1. 
In the case of Test 2, Figure $6 \mathrm{~b}$ indicates that the event to be analyzed lies close to the centers of Samples 2 and 3. In this situation, Test 2 is put together with Samples 2 and 3 for further cluster analysis, respectively. The results of the second cluster analysis for just Sample 2, Sample 3 and Test 2 are given in Figure 8. It shows that the distance between Test 2 and Sample 2 is 1.82 (Figure 8a) which is shorter than that between Test 2 and Sample 3 (1.87, as shown in Figure 8b). This means that Test 2 is closer to Sample 2 which corresponds to a moderate rockburst. Therefore, the rockburst intensity warning result for Test 2 is 'moderate rockburst'. The actual rockburst that occurred in Test 2 (Table 2) was moderate and so the predicted result is again in good agreement with the actual situation.

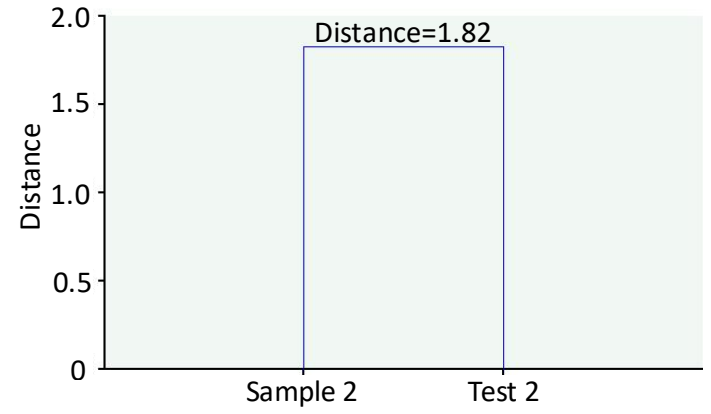

(a)

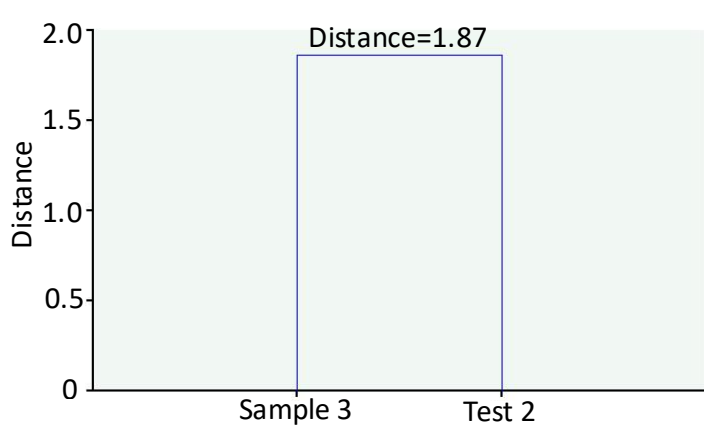

(b)

Figure 8. Results of the second clustering analysis carried out for Test 2 showing the distances between:

(a) Test 2 and Sample 2; (b) Test 2 and Sample 3.

In the case of Test 3, Figure 6c shows that the event to be analyzed again lies closest to the centers of Sample 2 and Sample 3. Therefore, Test 3 is put together with Sample 2 and Sample 3 and subjected to cluster analysis once again giving the results shown in Figure 9. This time, Test 3 turns out to be closer to Sample 3 (1.67) than Sample 2 (2.08). Sample 3 corresponds to the occurrence of a slightly intense rockburst and so the rockburst intensity warning result for Test 3 is 'slight rockburst'. The actual rockburst that occurred in Test 3 (Table 2) was slightly intense which agrees with the predicted result.

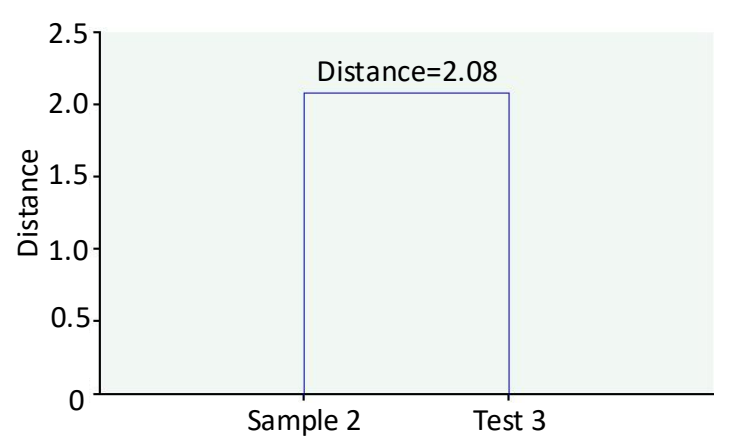

(a)

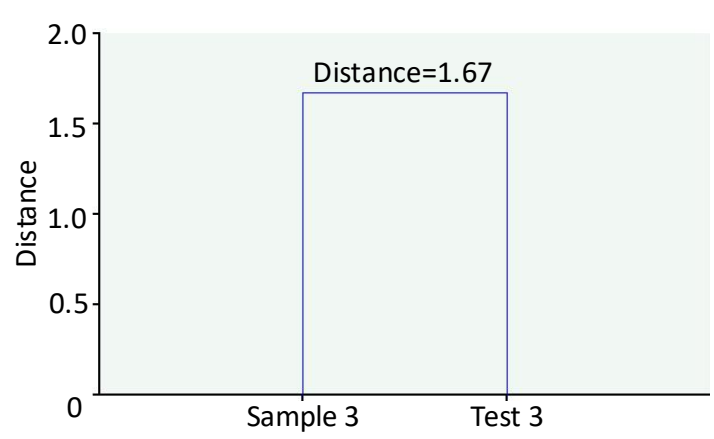

(b)

Figure 9. Results of the second clustering analysis carried out for Test 3 showing the distances between: (a) Test 3 and Sample 2; (b) Test 3 and Sample 3.

In the case of Test 4, Figure $6 \mathrm{~d}$ shows that there is a sample event that lies closest to the event to be analyzed. As can be seen, Test 4 is classified into a group with Sample 4 (no rockburst) that is far away from the other three sample cases. Thus, Test 4 has similar microseismicity to that associated with the development of a rockburst whose intensity falls in the 'none' category. That is, the rockburst risk is low and so the rockburst intensity warning result for Test 4 is 'no rockburst'. The actual rockburst intensity for Test 4 is also shown in Table 2 and is in agreement with the predicted result.

The test cases above show that accurate rockburst intensity warnings can be generated using the proposed method based on just four sample events recorded during the initial period of MS 
monitoring. A more complete summary of the advantages and innovative nature of the proposed rockburst intensity warning method is as follows:

(1) Compared with traditional methods based on microseismicity, the proposed method does not require a large number of samples. In fact, only one case of each rockburst intensity is required at most. It is therefore suitable for use in the early stages of MS monitoring when there are only a few rockburst cases available for analysis.

(2) The proposed method involves multiple parameters. It therefore avoids the problem of one-sidedness and other limitations that arise when rockburst warnings are based on a single MS parameter. At the same time, it solves the problem of incongruity between different MS parameters. That is, rockburst warnings based on different MS parameters are often inconsistent. This can be illustrated using Test 1 as an example. A rockburst intensity warning based solely on a cumulative number of MS events would suggest that a moderate rockburst is likely to occur (the cumulative number of MS events is 15, close to that recorded in Sample 2 which corresponds to a moderate rockburst). On the other hand, the rockburst warning based on cumulative MS energy is intense (the cumulative MS energy is 6.587, close to that of Sample 1 which corresponds to an intense rockburst). Therefore, it is difficult to be consistent if warnings are based on single MS parameters.

(3) The proposed method introduces the idea of a second cluster analysis when the event to be analyzed is close to the centers of two samples events. Cluster analysis is conducted again using the event to be analyzed and the two sample events separately.

\section{Discussion}

From the results above we can find that the rockburst intensity warning is generated according to the results of the cluster analysis or after a second cluster analysis. The times of cluster analysis for getting the rockburst intensity warning results for different tests are different. For the cases of Test 1 and Test 4, rockburst intensity warning results can be obtained after just using cluster analysis once. However, for the cases of Tests 2 and 3, rockburst intensity warning results were obtained after using a second cluster analysis. Why did Tests 2 and 3 need more times of cluster analysis than Tests 1 and 4 ? In the process of clustering analysis, the event to be analyzed (test event) and the sample events are regarded as independent classes [37]. It means that the test event and the sample events are all independent classes. Then we calculate the distance between these various classes and merge the nearest two classes into one class. In this step, not only the distance between the test event and the sample events are calculated, but also the distance between different sample events. For Test 2 , the distance between Samples 2 and 3 is shorter than that between Sample 2 and Test 2. Additionally, it is shorter than that between Sample 3 and Test 2. Therefore, Samples 2 and 3 were first merged into one class (see in Figure 6b), and Test 2 is close to the two sample events. In this case, a second cluster analysis is needed for getting the rockburst intensity warning result of Test 2 . For Test 3 , the distance between Samples 2 and 3 is shorter than that between Sample 2 and Test 3. Additionally, it is shorter than that between Sample 3 and Test 3. Therefore, Samples 2 and 3 were first merged into one class (see in Figure 6c), and Test 3 is close to the two sample events. In this case, a second cluster analysis is needed for getting the rockburst intensity warning result of Test 3.

The sample events were put together for cluster analysis. Results of the cluster analyses carried out for the four sample events are given in Figure 10. We can find that Samples 2 and 3 are the nearest two samples. They were merged into one class. Figure 11 shows the distance among the four sample events after clustering analysis more directly. The distance between Samples 1 and 2 is 1.44. The distance between Samples 2 and 3 is 0.98. The distance between Samples 3 and 4 is 1.97. It means that Samples 2 and 3 are very close to each other. Since Sample 2 (moderate rockburst) and Sample 3 (slight rockburst) are very close to each other, they were likely to be merged into one class first in the process of cluster analysis. Therefore, a second cluster analysis for intensity warnings of slight and moderate rockbursts, such as Tests 2 and 3 , is likely to be needed. 


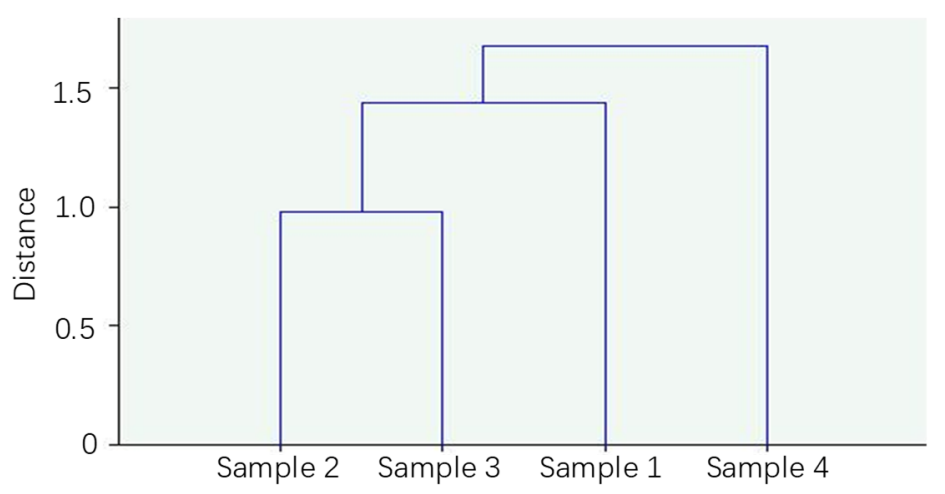

Figure 10. Results of clustering analysis carried out for the four sample events.

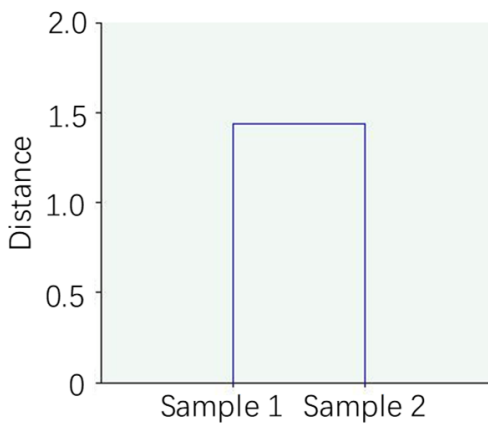

(a)

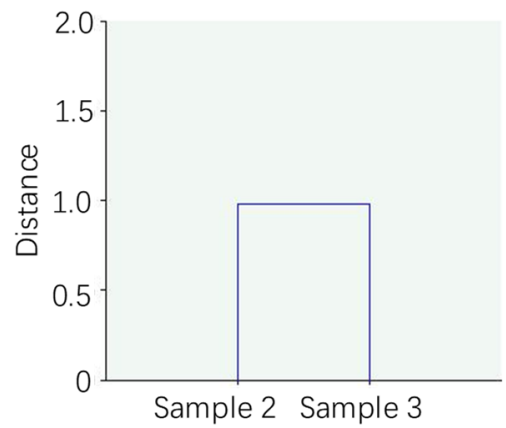

(b)

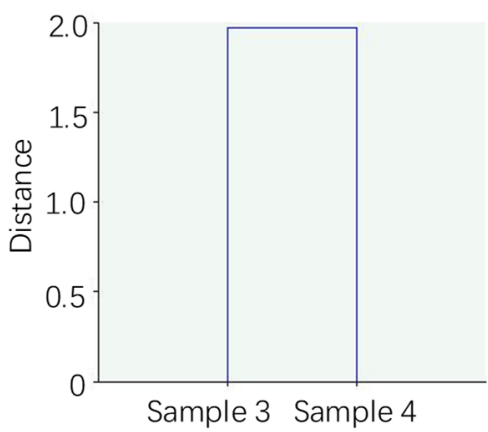

(c)

Figure 11. Distances among the four sample events after clustering analysis, showing: (a) Samples 1 and 2; (b) Samples 2 and 3; (c) Samples 3 and 4.

\section{Conclusions}

A microseismicity-based rockburst intensity warning method is proposed in this paper that is suitable for use in deep tunnels in the initial period of MS monitoring. The method uses no more than five sample rockbursts cases and derives six MS parameters for each case via MS monitoring. Then, the same six MS parameters are determined via MS monitoring for subsequent events to be analyzed. This information is combined with the sample events and subjected to cluster analysis. Finally, a rockburst intensity warning is generated according to the results of the cluster analysis (or after a second cluster analysis). The proposed method does not require a large number of samples (only one case per rockburst intensity category, at most) which makes it suitable for deriving rockburst warnings in the early stages of MS monitoring. Furthermore, as it is a multi-parameter warning method, it avoids the bias often encountered when a single MS parameter is used to generate warnings. It also solves the problem of incongruity between different MS parameters. Meanwhile, the proposed method introduces the idea of a second cluster analysis to improve prediction accuracy.

The engineering application considered in this work (using MS data recorded in the deep tunnels of the Jinping II hydropower station in China) shows that the proposed method is capable of generating accurate rockburst intensity warnings. The correct rockburst intensities were predicted in two of the four test cases considered using just one cluster analysis; the other two were correctly predicted after performing the second cluster analysis.

The proposed method enriches the existing microseismicity-based rockburst warning methods. It is hoped that the warning results can be used to guide the prevention and control of rockbursts in the initial period when MS monitoring is first performed in deep tunnels, hence, saving lives and preventing financial losses in this stage of the construction process. In additional, the methodology can also enrich the current list of available techniques for stability analysis of other infrastructure 
components, such as bridges, retaining walls, etc., based on microseismicity in the initial period of MS monitoring.

Author Contributions: Methodology, G.F.; validation, M.L., and Y.Y.; formal analysis, M.L.; investigation, Y.Y.; resources, G.F.; writing - Original draft preparation, Y.F.; writing—Review and editing, G.F., and M.L.; supervision, G.F. All authors have read and agreed to the published version of the manuscript.

Funding: This research was funded by the National Natural Science Foundation of China (grant No. 41972295) and the Research Project of the Guangxi Key Laboratory of Disaster Prevention and Engineering Safety, Guangxi University (grant No. 2019ZDK034).

Conflicts of Interest: The authors declare no conflict of interest.

\section{Appendix A}

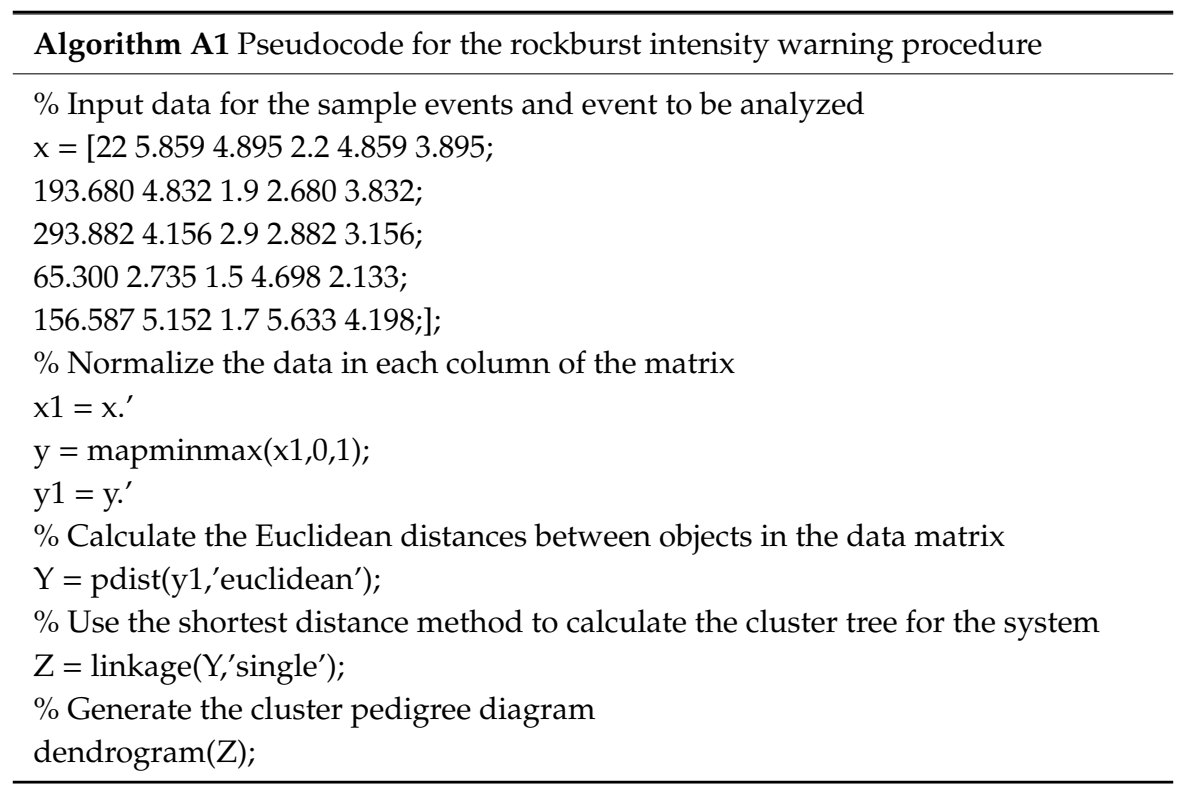

\section{References}

1. Hedley, D.G.F. Rockburst Handbook for Ontario Hardrock Mines; CANMET Special Report SP92-1E; Canada Center for Mineral and Energy Technology: Toronto, ON, Canada, 1992.

2. Kaiser, P.K.; Tannant, D.D.; McCreath, D.R. Canadian Rockburst Support Handbook; Geomechanics Research Centre, Laurentian University: Sudbury, ON, Canada, 1996.

3. Zhang, C.Q.; Feng, X.T.; Zhou, H.; Qiu, S.L.; Wu, W.P. Rockmass damage development following two extremely intense rockbursts in deep tunnels at Jinping II hydropower station, southwestern China. Bull. Eng. Geol. Environ. 2013, 72, 237-247. [CrossRef]

4. Naji, A.M.; Rehman, H.; Emad, M.Z.; Ahmad, S.; Kim, J.J.; Yoo, H. Static and dynamic influence of the shear zone on rockburst occurrence in the headrace tunnel of the Neelum Jhelum hydropower project, Pakistan. Energies 2019, 12, 2124. [CrossRef]

5. Feng, X.T. Rockburst: Mechanism, Monitoring, Warning and Mitigation; Butterworth-Heinemann: Oxford, UK, 2017.

6. Mendecki, A.J. Seismic Monitoring in Mines; Chapman \& Hall: London, UK, 1997.

7. Poplawski, R.F. Seismic parameters and rockburst hazard at Mt Charlotte mine. Int. J. Rock Mech. Min. Sci. 1997, 34, 1213-1228. [CrossRef]

8. Tang, L.Z. Study on Monitoring and Prediction of Seismicity and Rockburst in a Deep Mine; Central South University: Changsha, China, 2008.

9. Trifu, C.I.; Suorineni, F.T. Use of MS monitoring for rockburst management at VALE INCO mines. In Proceedings of Seventh International Symposium on Rock burst and Seismicity in Mines, Dalian, China, 21-23 August 2009; Renton Press: New York, NY, USA, 2009; pp. 1105-1114. 
10. Shan, Z.G.; Yan, P. Management of rock bursts during excavation of the deep tunnels in Jinping II Hydropower Station. Bull. Eng. Geol. Environ. 2010, 69, 353-363. [CrossRef]

11. Feng, G.L.; Feng, X.T.; Chen, B.R.; Xiao, Y.X.; Yu, Y. A microseismic method for dynamic warning of rockburst development processes in tunnels. Rock Mech. Rock Eng. 2015, 48, 2061-2076. [CrossRef]

12. Zhao, T.B.; Guo, W.Y.; Tan, Y.L.; Yin, Y.C.; Cai, L.S.; Pan, J.F. Case studies of rock bursts under complicated geological conditions during multi-seam mining at a depth of $800 \mathrm{~m}$. Rock Mech. Rock Eng. 2018, 51, 1539-1564. [CrossRef]

13. Wang, Z.Y.; Dou, L.M.; Wang, G.F. Mechanism analysis of roadway rockbursts induced by dynamic mining loading and its application. Energies 2018, 11, 2313. [CrossRef]

14. Kong, P.; Jiang, L.; Jiang, J.; Wu, Y.; Chen, L.; Ning, J. Numerical analysis of roadway rock-burst hazard under superposed dynamic and static loads. Energies 2019, 12, 3761. [CrossRef]

15. He, S.; Song, D.; Li, Z.; He, X.; Chen, J.; Zhong, T.; Lou, Q. Mechanism and prevention of rockburst in steeply inclined and extremely thick coal seams for fully mechanized top-coal caving mining and under gob filling conditions. Energies 2020,13, 1362. [CrossRef]

16. Feng, G.L.; Xia, G.Q.; Chen, B.R.; Xiao, Y.X.; Zhou, R.C. A method for rockburst prediction in the deep tunnels of hydropower stations based on the monitored microseismicity and an optimized probabilistic neural network model. Sustainability 2019, 11, 3212. [CrossRef]

17. Gibowicz, S.J.; Young, R.P.; Talebi, S.; Rawlence, D.J. Source parameters of seismic events at the underground research laboratory in Manitoba, Canada-scaling relations for events with moment magnitude smaller than -2. Bull. Seismol. Soc. Am. 1991, 81, 1157-1182.

18. Mccreary, R.; Mcgaughey, J.; Potvin, Y. Results from MS monitoring, conventional instrumentation, and tomography surveys in the creation and thinning of a burst-prone sill pillar. Pure Appl. Geophys. 1992, 139, 349-373. [CrossRef]

19. Van, A.G.; Butler, A.G. Applications of quantitative seismology in South Africa gold mines. In Proceedings of Third International Symposium on Rockbursts and Seismicity in Mines, Kingston, ON, Canada, 16-18 August 1993; A.A.Balkema: Rotterdam, The Netherland, 1993; pp. 261-266.

20. Becka, D.A.; Brady, B.H.G. Evaluation and application of controlling parameters for seismic events in hard-rock mines. Int. J. Rock Mech. Min. Sci. 2002, 39, 633-642. [CrossRef]

21. Li, T.; Cai, M.F.; Cai, M. A review of mining-induced seismicity in China. Int. J. Rock Mech. Min. Sci. 2007, 44, 1149-1171. [CrossRef]

22. Liu, J.P.; Feng, X.T.; Li, Y.H.; Xu, S.D.; Sheng, Y. Studies on temporal and spatial variation of MS activities in a deep metal mine. Int. J. Rock Mech. Min. Sci. 2013, 60, 171-179. [CrossRef]

23. Lu, C.P.; Liu, G.J.; Liu, Y.; Zhang, N.; Xue, J.H.; Zhang, L. Microseismic multi-parameter characteristics of rockburst hazard induced by hard roof fall and high stress concentration. Int. J. Rock Mech. Min. Sci. 2015, 76, 18-32. [CrossRef]

24. Cao, A.Y.; Dou, L.M.; Wang, C.B.; Yao, X.X.; Dong, J.Y.; Gu, Y. Microseismic precursory characteristics of rock burst hazard in mining areas near a large residual coal pillar: A case study from Xuzhuang coal mine, Xuzhou, China. Rock Mech. Rock Eng. 2016, 49, 4407-4422. [CrossRef]

25. Feng, X.T.; Chen, B.R.; Li, S.J.; Zhang, C.Q.; Xiao, Y.X.; Feng, G.L.; Zhou, H.; Qiu, S.L.; Zhao, Z.N.; Yu, Y.; et al. Study on the evolution process of rockbursts in deep tunnels. J. Rock Mech. Geotech. Eng. 2012, 4, $289-295$. [CrossRef]

26. Xu, N.W.; Li, T.B.; Dai, F.; Zhang, R.; Tang, C.A.; Tang, L.X. Microseismic monitoring of strainburst activities in deep tunnels at the Jinping II hydropower station, China. Rock Mech. Rock Eng. 2016, 49, 981-1000. [CrossRef]

27. Ma, T.H.; Tang, C.A.; Tang, S.B.; Kuang, L.; Yu, Q.; Kong, D.Q.; Zhu, X. Rockburst mechanism and prediction based on microseismic monitoring. Int. J. Rock Mech. Min. Sci. 2018, 110, 177-188. [CrossRef]

28. Zhang, H.; Chen, L.; Chen, S.G.; Sun, J.C.; Yang, J.S. The spatiotemporal distribution law of microseismic events and rockburst characteristics of the deeply buried tunnel group. Energies 2018, 11, 3257. [CrossRef]

29. Feng, G.L.; Feng, X.T.; Chen, B.R.; Xiao, Y.X.; Zhao, Z.N. Effects of structural planes on the microseismicity associated with rockburst development processes in deep tunnels of the Jinping-II Hydropower Station, China. Tunn. Undergr. Sp. Tech. 2019, 84, 273-280. [CrossRef] 
30. Feng, G.L.; Feng, X.T.; Xiao, Y.X.; Yao, Z.B.; Hu, L.; Niu, W.J.; Li, T. Characteristic microseismicity during the development process of intermittent rockburst in a deep railway tunnel. Int. J. Rock Mech. Min. Sci. 2019, 124, 104135. [CrossRef]

31. He, S.Q.; Song, D.Z.; Li, Z.L.; He, X.Q.; Chen, J.Q.; Li, D.H.; Tian, X.H. Precursor of spatio-temporal evolution law of MS and AE activities for rock burst warning in steeply inclined and extremely thick coal seams under caving mining conditions. Rock Mech. Rock Eng. 2019, 52, 2415-2435. [CrossRef]

32. Liu, F.; Tang, C.A.; Ma, T.H.; Tang, L.X. Characterizing rockbursts along a structural plane in a tunnel of the Hanjiang-to-Weihe river diversion project by microseismic monitoring. Rock Mech. Rock Eng. 2019, 52, 1835-1856. [CrossRef]

33. Zhang, H.; Ma, C.; Li, T. Quantitative evaluation of the "non-enclosed" microseismic array: A case study in a deeply buried twin-tube tunnel. Energies 2019, 12, 2006. [CrossRef]

34. Peng, P.G.; Jiang, Y.J.; Wang, L.G.; He, Z.X. Microseismic event location by considering the influence of the empty area in an excavated tunnel. Sensors 2020, 20, 574. [CrossRef]

35. Feng, G.L.; Feng, X.T.; Chen, B.R.; Xiao, Y.X.; Liu, G.F.; Zhang, W.; Hu, L. Characteristics of microseismicity during breakthrough in deep tunnels: Case study of the Jinping-II hydropower station in China. Int. J. Geomech. 2020, 20, 04019163. [CrossRef]

36. Ma, C.C.; Li, T.B.; Zhang, H. Microseismic and precursor analysis of high-stress hazards in tunnels: A case comparison of rockburst and fall of ground. Eng. Geol. 2020, 265, 105435. [CrossRef]

37. Everitt, B.S.; Landau, S.; Leese, M. Cluster Analysis; Oxford University Press: New York, NY, USA, 2001.

38. Chen, B.R.; Feng, X.T.; Li, Q.P.; Luo, R.Z.; Li, S.J. Rock burst intensity classification based on the radiated energy with damage intensity at Jinping II Hydropower Station, China. Rock Mech. Rock Eng. 2015, 48, 289-303. [CrossRef]

39. Zhang, C.Q.; Feng, X.T.; Zhou, H.; Qiu, S.L.; Wu, W.P. Case histories of four extremely intense rockbursts in deep tunnels. Rock Mech. Rock Eng. 2012, 45, 275-288. [CrossRef]

(C) 2020 by the authors. Licensee MDPI, Basel, Switzerland. This article is an open access article distributed under the terms and conditions of the Creative Commons Attribution (CC BY) license (http://creativecommons.org/licenses/by/4.0/). 